\title{
A novel tertiary bromine-functionalized thermal iniferter for controlled radical polymerization
}

\author{
Mukesh Kumar and Tharanikkarasu Kannan
}

A novel terminal tertiary bromine-containing thermal iniferter, 1,1,2,2-tetraphenylethane-1,2-diyl bis(2-bromo-2methylpropanoate) (TPEBMP), was prepared from 1,1,2,2-tetraphenyl-1,2-ethanediol and $\alpha$-bromoisobutyryl bromide. The controlled radical polymerization of methyl methacrylate and styrene was successfully carried out using TPEBMP at $70^{\circ} \mathrm{C}$. During the polymerization, the number average molecular weight increased linearly with increasing conversion. Number average molecular weight was determined by gel permeation chromatography, and was found to be similar to the theoretical molecular weight. The novel iniferter TPEBMP and the polymers prepared from this iniferter were characterized by spectral, thermal and chromatographic methods. The glass transition temperature $\left(T_{\mathrm{g}}\right)$ of the poly(methyl methacrylate) was observed at $127^{\circ} \mathrm{C}$, whereas the $T_{\mathrm{g}}$ of the polystyrene was observed at $102{ }^{\circ} \mathrm{C}$. Because the resulting polystyrene and poly(methyl methacrylate) consist of tertiary bromine at both ends of the chains, these polymers can be used as macroinitiators for atom transfer radical polymerization to synthesize tri-block copolymers.

Polymer Journal (2010) 42, 916-922; doi:10.1038/pj.2010.92; published online 20 October 2010

Keywords: 1,1,2,2-tetraphenyl-1,2-ethanediol; controlled radical polymerization; iniferter; polystyrene; poly(methyl methacrylate)

\section{INTRODUCTION}

Living anionic polymerization can be used to synthesize the block copolymers of a desired molecular weight and end functionality, ${ }^{1,2}$ but this process requires rigorous polymerization conditions such as high vacuum and highly purified monomers and solvents. In addition, living anionic polymerization can only be used to polymerize hydrocarbon monomers, and the polymerization of polar monomers through anionic polymerization leads to unwanted side reactions. On the other hand, free radical polymerization is the preferred method for manufacturing a wide variety of polymers because it does not require rigorous polymerization conditions, and it tolerates trace impurities. However, the main drawback of radical polymerization is the uncontrolled molecular weight build-up, which results in polymers with a broad molecular weight distribution (MWD). Many controlled radical polymerization (CRP) methods have been proposed to date to control the molecular weight and MWD. ${ }^{3-5} \mathrm{~A}$ wide variety of polymers can be synthesized through CRP with controlled molecular weights, narrow MWDs and desired end groups that are difficult to achieve with conventional radical polymerization. ${ }^{4}$

One effective CRP method is controlled molecular weight build-up using the stable nitroxide radical 2,2,6,6-tetramethylpiperidine$\mathrm{N}$-oxyl $l^{6}$ as a reversible capping agent. However, the high temperature (for example, $130{ }^{\circ} \mathrm{C}$ for the polymerization of styrene) that is required to reversibly cleave the bond between the 2,2,6,6-tetramethylpiperidine- $N$-oxyl moiety and the growing polymer chain confines the application of this route to very few monomers. Atom transfer radical polymerization (ATRP) $)^{5}$ is another effective CRP method that has been proposed for the polymerization of a variety of vinyl monomers at a lower polymerization temperature (for example, $100-110^{\circ} \mathrm{C}$ for the polymerization of styrene) than the 2,2,6,6-tetramethylpiperidine$N$-oxyl system. Because ATRP is catalyzed by transition metal halides, such as copper (I) bromide, the presence of catalytic amounts of metal in the final polymers is the main drawback of this route. ${ }^{7}$ Polymerization through iniferters, proposed by Otsu et al. ${ }^{8,9}$ in 1982, is another CRP route. The iniferter approach does not have any metal recovery issues as in the case of ATRP, and hence, this route is more eco-friendly than the ATRP route. Therefore, this paper attempts to synthesize a novel iniferter for CRP.

Iniferters act as initiators as well as reversible radical chain transfer/ terminating agents in radical polymerization. As a result, reversible primary radical termination or transfer reactions are generally observed more extent in this route. Iniferters can be classified as photoiniferters and thermal iniferters. Photoiniferters are mainly $\mathrm{N}, \mathrm{N}$ diethyldithiocarbamyl group-bearing compounds, ${ }^{9-12}$ whereas thermal iniferters, apart from phenylazotriphenylmethane, ${ }^{13}$ are usually carbon-carbon labile bond-containing compounds, such as tetraphenylsuccinodinitrile, ${ }^{14}$ hydroxy-2-( $p$-tolylaminocarbonyloxy)-1,1,2, 2-tetraphenylethane, ${ }^{15}$ tetra( $p$-methoxy phenyl) succinodinitrile, ${ }^{16}$ pentaphenylethane, ${ }^{16}$ 1,1,2,2-tetraphenyl-1,2-bis(trimethylsilyloxy)ethane $^{17}$ and 1,1,2,2-tetraphenyl-1,2-bis(phenoxy)-ethane. ${ }^{18}$ 1,1,2,2Tetraphenyl-1,2-ethanediol (TPED) has also been used as a radical initiator, but it does not proceed via the CRP mechanism ${ }^{19,20}$ due to 
the occurrence of a side reaction during the initiation of the monomer. To avoid this side reaction, the $\mathrm{OH}$ groups of TPED were reacted with diisocyanate, and the resulting polyurethane iniferter was used to polymerize vinyl monomers via a 'living' radical mechanism. ${ }^{21-23}$ Similarly, in this study, the $\mathrm{OH}$ groups of TPED were modified. A novel thermal iniferter was synthesized by reacting TPED with $\alpha$-bromoisobutyryl bromide, and the resulting compound was used as a thermal iniferter for the polymerization of methyl methacrylate (MMA) and styrene.

\section{EXPERIMENTAL PROCEDURE}

\section{Materials}

Styrene (Aldrich, St Louis, MO, USA) and MMA (CDH, Delhi, India) were purified using conventional purification methods. The purified monomers were distilled under vacuum and the middle fractions were stored at $0-4{ }^{\circ} \mathrm{C}$ until they were used. $\alpha$-Bromoisobutyryl bromide was obtained from Aldrich and was used without further purification. Diethyl ether and tetrahydrofuran (THF) were purchased from S.D. Fine Chemicals, Mumbai, India and purified by distillation over sodium-benzophenone complex just before use. All other chemicals were of analytical grade and were used as received.

\section{Synthesis of TPED}

TPED was prepared according to a photochemical method as described in the literature. ${ }^{24}$

Elemental analysis: $\mathrm{C}_{26} \mathrm{H}_{22} \mathrm{O}_{2}$ : (calculated, \%) $\mathrm{C}=85.212, \mathrm{H}=6.050, \mathrm{O}=8.732$.

(Observed, \%) $\mathrm{C}=85.220, \mathrm{H}=6.132, \mathrm{O}=8.648$.

${ }^{1} \mathrm{H}$ nuclear magnetic resonance (NMR; $\delta$ in p.p.m., $\mathrm{CDCl}_{3}, 300 \mathrm{MHz}$ ): 3.02 (s, OH, $2 \mathrm{H}$ ), 7.00-7.30 (m, phenyl, $20 \mathrm{H}$ ).

${ }^{13} \mathrm{C}$ NMR ( $\delta$ in p.p.m., $\mathrm{CDCl}_{3}, 75 \mathrm{MHz}$ ): 83.00, 125.78, 125.88, 126.12, $126.38,127.05,127.44,144.22$.

\section{Synthesis of 1,1,2,2-tetraphenylethane-1,2-diyl bis(2-bromo-2- methylpropanoate) (TPEBMP)}

TPEBMP was synthesized from TPED and $\alpha$-bromoisobutyryl bromide. TPED $(13.6 \mathrm{mmol})$ was added to a $500-\mathrm{ml}$ three-necked round-bottom flask fitted with a reflux condenser, a magnetic stirrer, and a dropping funnel. To this, $300 \mathrm{ml}$ of anhydrous diethyl ether was added under a nitrogen atmosphere. Then, $N, N^{\prime}$-diethyl aniline $(27.2 \mathrm{mmol})$ was added followed by $\alpha$-bromoisobutyryl bromide $(27.2 \mathrm{mmol})$. The reaction mixture was refluxed, and after $30 \mathrm{~min}$, diethyl aniline hydrobromide began to precipitate as a white solid. After the reaction reached completion $(\sim 6 \mathrm{~h})$ as determined by thin layer chromatography, $100 \mathrm{ml}$ of distilled water was added to the reaction mixture and stirring was continued until the diethyl aniline hydrobromide salt was dissolved. The ether layer was separated and washed three times with $5 \%$ aqueous hydrochloric acid followed by a saturated aqueous sodium hydrogen carbonate solution. Finally, the ether layer was again washed with distilled water until the solution reached neutral $\mathrm{pH}$. The ether portion was dried over anhydrous sodium sulfate overnight. Ether was distilled under reduced pressure, yielding the novel iniferter as a white crystalline solid at a yield of $86 \%$.

Elemental analysis for $\mathrm{C}_{34} \mathrm{H}_{32} \mathrm{O}_{4} \mathrm{Br}_{2}$ : (Calculated, \%) $\mathrm{C}=61.461, \mathrm{H}=4.854$, $\mathrm{O}=9.632, \mathrm{Br}=24.053$. (Observed, \%) $\mathrm{C}=61.35, \mathrm{H}=4.90, \mathrm{O}=9.61$.

Fourier-transform infrared (FT-IR) $\left(\mathrm{KBr}, \mathrm{cm}^{-1}\right): 1715$ (C=O str.), 2922 (Ar-H str.), 2854 (C-H str.).

${ }^{1} \mathrm{H}$ NMR ( $\delta$ in p.p.m., $\left.\mathrm{CDCl}_{3}, 300 \mathrm{MHz}\right): 1.94\left(-\mathrm{CH}_{3}, 12 \mathrm{H}\right), 7.14-7.31$ (phenyl, $20 \mathrm{H}$ ).

${ }^{13} \mathrm{C}$ NMR $\left(\delta\right.$ in p.p.m., $\mathrm{CDCl}_{3}, 75 \mathrm{MHz}$ ): $30.60,55.18,88.11,125.78,125.88$, $126.12,126.38,127.05,127.44,143.01,176.80$.

\section{CRP of MMA and styrene}

First, an appropriate amount of TPEBMP $\left(6.02 \times 10^{-4} \mathrm{moll}^{-1}\right)$ was added to a clean glass polymerization tube under a nitrogen atmosphere and was dissolved in dry THF. The required amount of monomer $\left(0.903 \mathrm{moll}^{-1}\right.$; iniferter:monomer $=1: 1500$ ) was then added to the reaction mixture and polymerization was carried out for a specified period of time at $70^{\circ} \mathrm{C}$ in a thermostated oil bath. After the specified reaction time, the polymerization was stopped by removing the tube from the oil bath and cooling in an ice-salt mixture. The resultant polymer solution was poured into a 10 -fold excess of methanol to obtain the polymer as a white precipitate. The resulting precipitate was filtered using a glass crucible, dried in an oven at $50^{\circ} \mathrm{C}$ and weighed. The conversion was determined by gravimetric method.

\section{Characterization}

Nuclear magnetic resonance (NMR) spectra were recorded on a Bruker DPX300 NMR instrument (Bruker, Billerica, MA, USA), and FT-IR spectra were recorded from $\mathrm{KBr}$ pellets on a Nicolet Impact 400 FT-IR spectrophotometer (Nicolet, Madison, WI, USA). Number average $\left(\bar{M}_{n}\right)$,weight average $\left(\bar{M}_{w}\right)$, molecular weights and MWD were determined using a Waters gel permeation chromatography (GPC) instrument equipped with a 2414 differential refractive index detector and two (HR 2 and HR 4) Waters $\mu$-styragel columns. Tetrahydrofuran was used as the eluent at a flow rate of $1.0 \mathrm{ml} \mathrm{min}^{-1}$, and the molecular weight calibrations were carried out using polystyrene standards. Differential scanning calorimetric studies were carried out using a TA Instruments DSC Q200 instrument (New Castle, DE, USA) at a heating rate of $10{ }^{\circ} \mathrm{C} \mathrm{min}^{-1}$ under a nitrogen atmosphere, and thermogravimetric analysis was carried out using a TA Instruments TGA Q50 instrument at a heating rate of $10^{\circ} \mathrm{C} \mathrm{min}^{-1}$ under a nitrogen atmosphere.

\section{RESULTS AND DISCUSSION}

TPED is a well known free radical initiator that is used in conventional radical polymerization, ${ }^{20}$ but it neither acts as an iniferter nor follows a CRP mechanism, because of the presence of $\mathrm{OH}$ groups. When TPED is used to polymerize a vinyl monomer, benzophenone is formed as the side product. ${ }^{22}$ To avoid this reaction, the $\mathrm{OH}$ groups of TPED were reacted with diisocyanates and the resulting compounds were used as macroiniferters in CRP. ${ }^{22,23}$ If the hydroxyl groups of TPED are converted to halogen groups, the product can be used for surface initiated polymerization by anchoring the initiator onto the clay surface. Keeping this in mind, the $\mathrm{OH}$ groups of TPED were effectively modified with $\alpha$-bromoisobutyryl bromide, resulting in the novel bromine-containing thermal iniferter TPEBMP.

\section{Synthesis and characterization of TPEBMP}

As shown in Scheme 1a, TPED was reacted with $\alpha$-bromoisobutyryl bromide, and the resulting novel iniferter was characterized by NMR spectroscopy. Figure 1 shows the ${ }^{1} \mathrm{H}$ NMR spectrum of the novel iniferter, TPEBMP. The absence of a peak corresponding to $\mathrm{OH}$ protons and the appearance of a new peak at 1.94 p.p.m. corresponding to the methyl protons present in TPEBMP confirms the formation of the novel iniferter. In the FT-IR spectrum of TPEBMP, a new peak at $1715 \mathrm{~cm}^{-1}$ is observed that corresponds to the carbonyl stretching vibrations of the newly formed ester groups. These results confirm the formation of the novel iniferter, TPEBMP.

\section{CRP studies}

The newly synthesized iniferter, TPEBMP, was used to polymerize MMA and styrene to study the mechanism of polymerization. Scheme $1 \mathrm{~b}$ shows a possible mechanism for the polymerization of MMA using the novel iniferter, TPEBMP. Similar to other iniferterbased polymerizations, primary radical termination and transfer reactions were more prevalent, resulting in the attachment of iniferter fragments at both ends of the polymers. Tables 1 and 2 show the results of the polymerization of MMA and styrene, respectively. The novel iniferter successfully polymerizes both MMA and styrene, and conversion increases with polymerization time. Figure 2 shows the time vs conversion and time vs $\ln [M]_{0} /[M]$ plots for MMA polymerization, and similar plots for styrene polymerization are shown in Figure 3. Here, $[M]_{0}$ and $[M]$ represent the initial monomer concentration and the monomer concentration at time $t$, respectively. The linear time vs $\ln \left([M]_{0} /[M]\right)$ plots show that the concentrations 
(a) Synthesis of TPEBMP

(b) Polymerization of MMA<smiles>CC(C)(C)C(=O)OC(c1ccccc1)(c1ccccc1)C(OC(=O)C(C)(C)Br)(c1ccccc1)c1ccccc1</smiles>

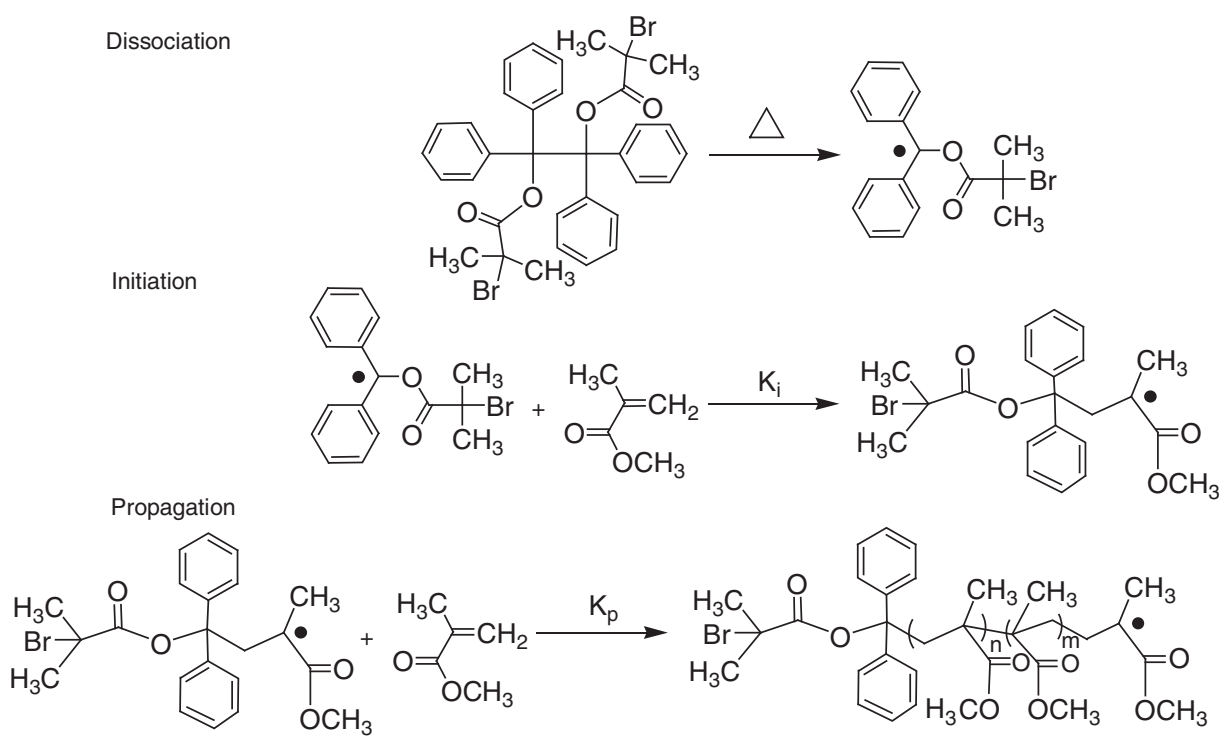

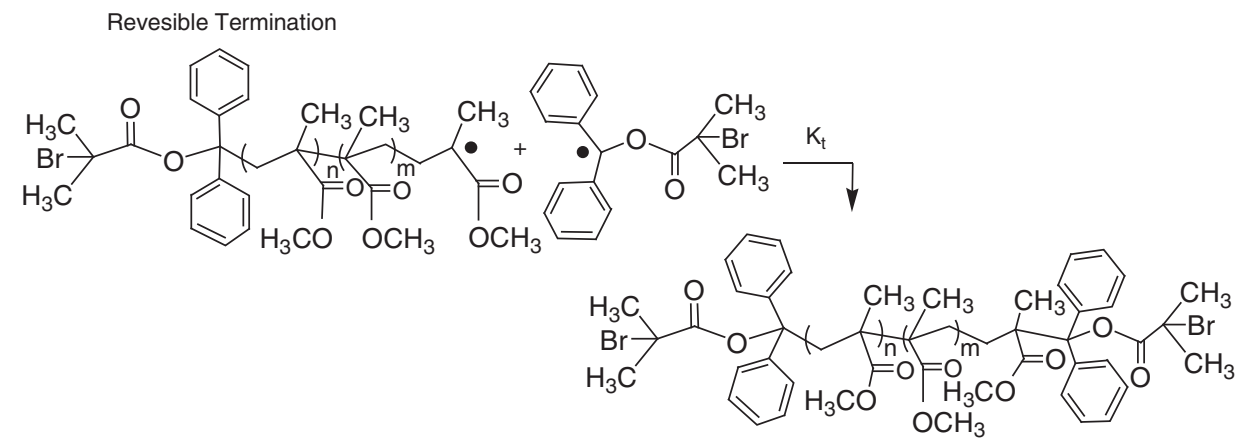

Scheme 1 (a) Synthesis of TPEBMP and (b) controlled radical polymerization of MMA using TPEBMP.

of propagating radicals were constant throughout the studied period of time. In the case of styrene polymerization, time vs conversion and time vs $\ln \left([M]_{0} /[M]\right)$ plots pass through the origin, which is a typical result of CRP. In the MMA polymerization, however, the time vs conversion and time vs $\ln \left([M]_{0} /[M]\right)$ plots do not pass through the origin. As reported in the literature, this may be due to an initial delay in reaching equilibrium between propagating radicals and dormant species. During this delay, the irreversible termination of some of the primary radicals may occur in MMA polymerization, resulting in the deviations that are observed in both the time vs conversion and the time vs $\ln \left([M]_{0} /[M]\right)$ plots. A similar result was reported for MMA polymerization through $\mathrm{ATRP}^{25}$ and iniferter-based CRP. ${ }^{26}$ To further confirm the presence of CRP mechanism, the $\bar{M}_{n}$ calculated through GPC was plotted against conversion. Figures 4 and 5 show the conversion vs $\bar{M}_{n}$ plots for the polymerizations of MMA and styrene, respectively. In these figures, molecular weight increased linearly with conversion. This is also a characteristic result of CRP. However, in the case of MMA polymer- ization, the conversion vs $\bar{M}_{n}$ plot does not pass through the origin, which could be due to the presence of some amount of irreversible termination, as reported in the literature. ${ }^{25,26}$ Interestingly, in the case of styrene polymerization, the conversion vs $\bar{M}_{n}$ plot passes through the origin. The time vs $\ln [M]_{0} /[M]$ and conversion vs $\bar{M}_{n}$ plots demonstrate that the TPEBMP-initiated polymerization of MMA proceeds through a CRP mechanism, along with some irreversible termination reactions, whereas styrene polymerization undergoes CRP without significant amounts of irreversible termination reactions.

Figures 6 and 7 show GPC curves for the polymerization of MMA and styrene, respectively. As the polymerization time and conversion increase, the GPC curves shift from the lower molecular weight region to the higher molecular weight region. The MWD values of poly (methyl methacrylate) (PMMA) and polystyrene prepared through TPEBMP are also narrow. These results again confirm that the polymerizations of MMA and styrene that were initiated by the thermal iniferter TPEBMP occur through CRP mechanism. 


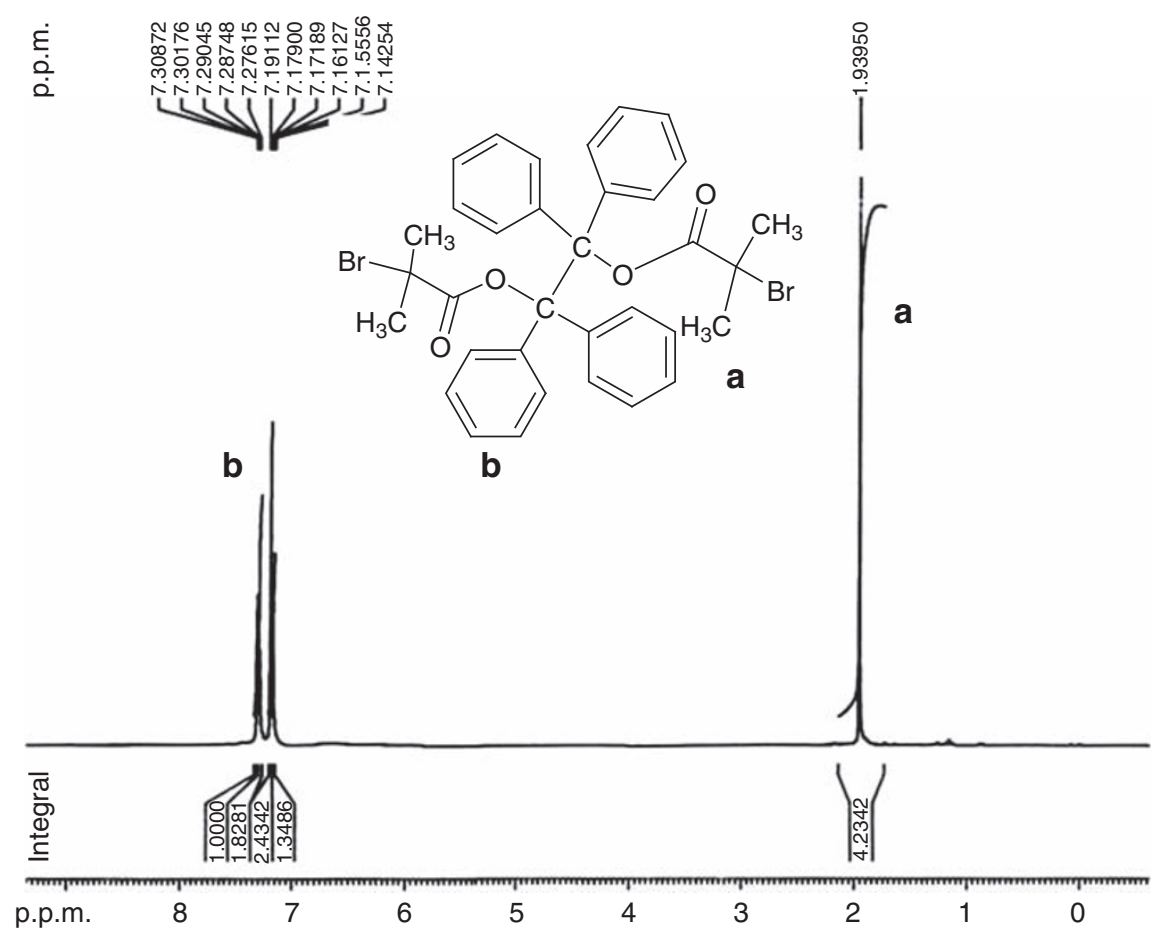

Figure $1^{1} \mathrm{H}$ NMR spectrum of the iniferter TPEBMP.

Table 1 Polymerization of MMA using TPEBMP at $70^{\circ} \mathrm{C}$ in THF

\begin{tabular}{|c|c|c|c|c|c|c|c|}
\hline \multirow[b]{2}{*}{ Code } & \multirow{2}{*}{$\begin{array}{l}\text { Time } \\
\text { (h) }\end{array}$} & \multirow{2}{*}{$\begin{array}{c}\text { Conversion }{ }^{\mathrm{a}} \\
\text { (\%) }\end{array}$} & \multirow{2}{*}{$\begin{array}{l}\bar{M}_{n, \mathrm{th}^{\mathrm{b}} \times} \\
10^{-4}\end{array}$} & \multirow{2}{*}{$\begin{array}{l}\bar{M}_{n, \mathrm{NMR}^{\mathrm{C}}} \\
\times 10^{-4}\end{array}$} & \multicolumn{3}{|c|}{ GPC results } \\
\hline & & & & & $\bar{M}_{w} \times 10^{-4}$ & $\bar{M}_{n} \times 10^{-4}$ & $\bar{M}_{w} / \bar{M}_{n}$ \\
\hline SM1 & 1 & 9.6 & 0.7296 & 1.0123 & 5.36 & 2.55 & 2.10 \\
\hline SM2 & 2 & 24.6 & 1.8538 & 1.7812 & 7.18 & 3.42 & 2.10 \\
\hline SM4 & 4 & 45.8 & 3.4428 & 5.9786 & 6.90 & 4.60 & 1.50 \\
\hline SM6 & 6 & 70.0 & 5.2566 & 6.9243 & 9.12 & 5.70 & 1.60 \\
\hline
\end{tabular}

Abbreviations: GPC, gel permeation chromatography; MMA, methyl methacrylate;

THF, tetrahydrofuran; TPEBMP, tetraphenylethane-1,2-diyl bis(2-bromo-2-methylpropanoate). aConversion was determined gravimetrically.

${ }^{\mathrm{b}} \bar{M}_{n, t h}=\left(\frac{[M]_{0}}{2[I]_{0}} \times\right.$ Monomer conversion $)+M$. Wt. of monomer.

${ }^{\mathrm{C}}$ Calculated by ${ }^{1} \mathrm{H}$ NMR.

Polymerization conditions: $[\text { TPEBMP }]_{0}=6.02 \times 10^{-4} \mathrm{~mol} \mathrm{I}^{-1}$; $[\mathrm{MMA}]_{0}=0.903 \mathrm{~mol} \mathrm{I}^{-1}$.

\section{Spectral studies of polymers}

${ }^{1} \mathrm{H}$ NMR spectra were recorded to understand the polymerization mechanism and the end groups that were present at both ends of the PMMA and polystyrene polymers synthesized here. Figure 8 shows the ${ }^{1} \mathrm{H}$ NMR spectrum of PMMA (SM6) synthesized through the novel iniferter, TPEBMP. The methylene protons of PMMA are observed at $1.77-1.82$ p.p.m. The methyl protons of PMMA resonate at $0.80,0.98$ and 1.17 p.p.m., corresponding to syndiotactic (rr), atactic (rm) and isotactic ( $\mathrm{mm}$ ) PMMA, respectively. The tacticity ratio of PMMA synthesized in the present investigation is rr:rm: $m=59: 33: 8$, which is similar to the reported tacticity ratio of PMMA synthesized through CRP. $^{27}$ The peak at 3.56-3.70 p.p.m. is due to the methyl protons of the ester unit present in the PMMA. The aromatic protons derived from the TPEBMP iniferter are observed at 7-7.3 p.p.m. The methyl
Table 2 Polymerization of styrene using TPEBMP at $70^{\circ} \mathrm{C}$ in THF

\begin{tabular}{lcccccc}
\hline & & & & \multicolumn{3}{c}{ GPC results } \\
\cline { 5 - 7 } Code & Time & Conversion & & & \\
\cline { 5 - 7 } & $(h)$ & $(\%)$ & $\bar{M}_{n, \text { th }^{\mathrm{b}} \times 10^{-4}}$ & $\bar{M}_{w} \times 10^{-4}$ & $\bar{M}_{n} \times 10^{-4}$ & $\bar{M}_{w} / \bar{M}_{n}$ \\
\hline SS6 & 6 & 15.0 & 1.1346 & 3.01 & 1.01 & 2.98 \\
SS12 & 12 & 31.1 & 2.3413 & 5.26 & 2.58 & 2.04 \\
SS18 & 18 & 54.0 & 4.0577 & 7.96 & 3.67 & 2.17 \\
SS24 & 24 & 65.8 & 4.9421 & 8.66 & 4.67 & 1.85
\end{tabular}

Abbreviations: GPC, gel permeation chromatography; MMA, methyl methacrylate;

THF, tetrahydrofuran; TPEBMP, tetraphenylethane-1,2-diyl bis(2-bromo-2-methylpropanoate) ${ }^{a}$ Conversion was determined gravimetrically.

${ }^{\mathrm{b}} \bar{M}_{n, t h}=\left(\frac{[M]_{0}}{2[I]_{0}} \times\right.$ Monomer conversion $)+M$. Wt. of monomer

Polymerization conditions: $[\text { TPEBMP }]_{0}=6.02 \times 10^{-4} \mathrm{~mol} \mathrm{I}^{-1}$; $[\text { Styrene }]_{0}=0.903 \mathrm{~mol} \mathrm{I}^{-1}$.

protons derived from the TPEBMP iniferter should be observed at 1.9 p.p.m. as in the case of the iniferter. However, these methyl protons are merged with the methylene protons of PMMA, which are observed at 1.77-1.82 p.p.m. The molecular weight of the PMMA was also determined from ${ }^{1} \mathrm{H}$ NMR spectra. These values were calculated from the peak intensity ratios between the methyl protons that are present in the ester groups of PMMA and the aromatic protons that are present in the TPEBMP fragments. In the ${ }^{1} \mathrm{H}$ NMR spectrum of polystyrene (SS12) that were prepared from TPEBMP iniferter, the methylene and methine protons of the polystyrene repeating unit are observed at 1.32 and 1.49 p.p.m., respectively. The aromatic protons on the phenyl rings of the iniferter fragments are merged with the aromatic protons of the phenyl rings that are present in the polystyrene repeating units, which are observed between 6.4 and 7.3 p.p.m. 


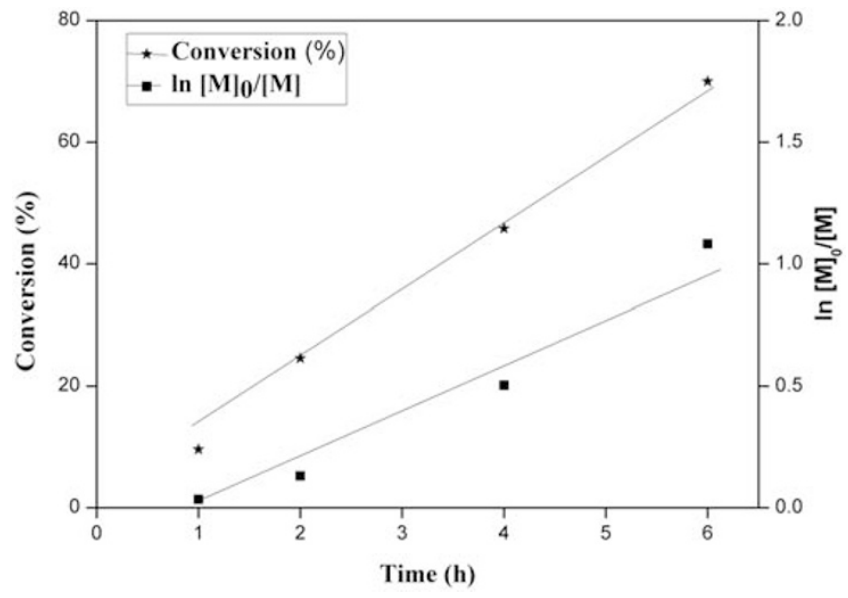

Figure 2 Time vs conversion and time vs $\ln [M]_{0} /[M]$ plots for the polymerization of MMA using TPEBMP. Polymerization conditions: $[\text { TPEBMP }]_{0}=6.02 \times 10^{-4} \mathrm{~mol} \mathrm{I}^{-1} ;[\mathrm{MMA}]_{0}=0.903 \mathrm{~mol} \mathrm{I}^{-1}$.

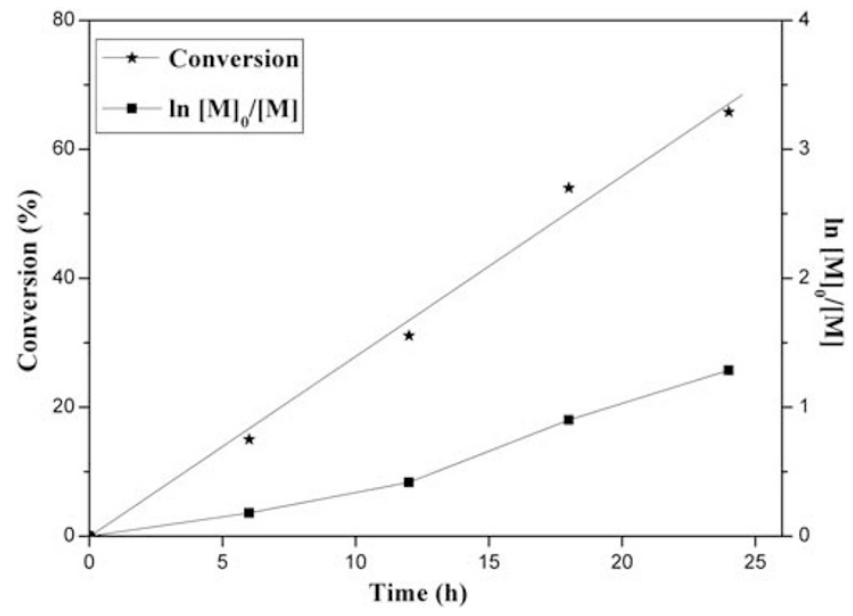

Figure 3 Time vs conversion and time vs $\ln [M]_{0} /[M]$ for the polymerization of styrene using TPEBMP. Polymerization conditions: [TPEBMP] $]_{0}=$ $6.02 \times 10^{-4} \mathrm{~mol} \mathrm{I}^{-1} ;$ [styrene $]_{0}=0.903 \mathrm{~mol} \mathrm{I}^{-1}$.

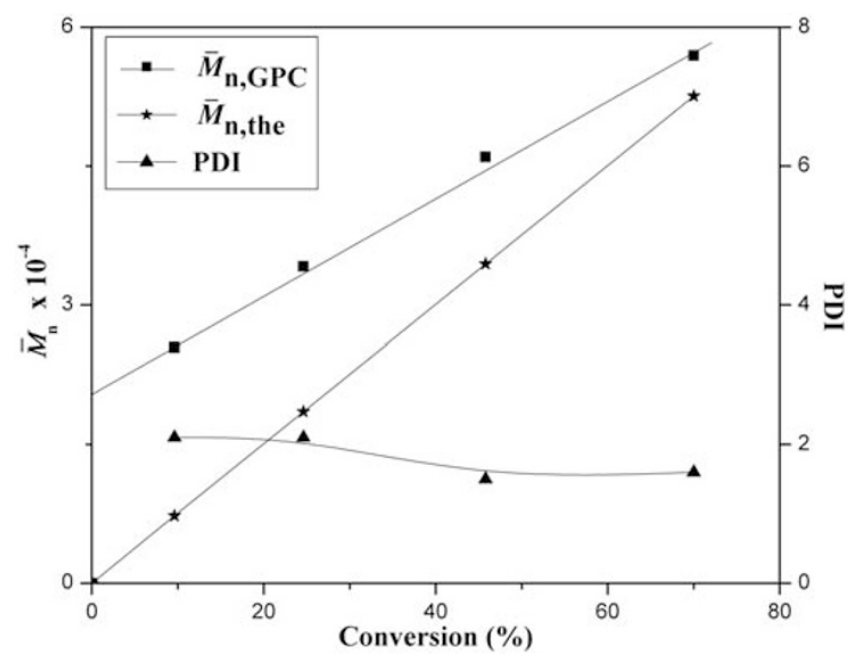

Figure 4 Conversion vs $\bar{M}_{n}$ and conversion vs polydispersity index (PDI; $\bar{M}_{w} / \bar{M}_{n}$ ) plots for the polymerization of MMA using TPEBMP. Polymerization conditions: $[\text { TPEBMP }]_{0}=6.02 \times 10^{-4} \mathrm{~mol} \mathrm{I}^{-1} ;[\mathrm{MMA}]_{0}=0.903 \mathrm{~mol} \mathrm{I}^{-1}$.

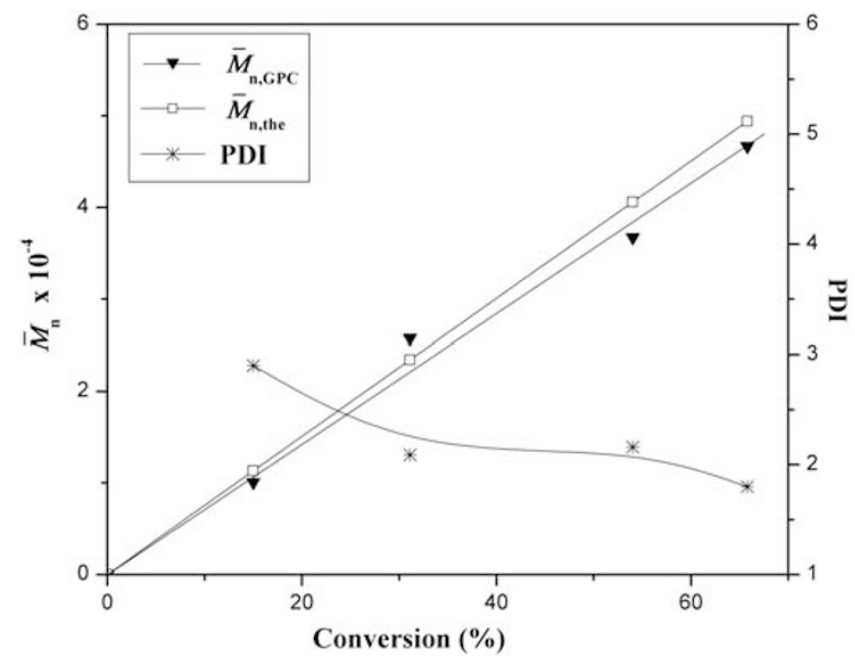

Figure 5 Conversion vs $\bar{M}_{n}$ and conversion vs polydispersity index (PDI; $\left.\bar{M}_{w} / \bar{M}_{n}\right)$ for the polymerization of styrene using TPEBMP; [TPEBMP] $]_{0}=$ $6.02 \times 10^{-4} \mathrm{~mol} \mathrm{I}^{-1} ;$ [styrene $_{0}=0.903 \mathrm{~mol} \mathrm{I}^{-1}$.

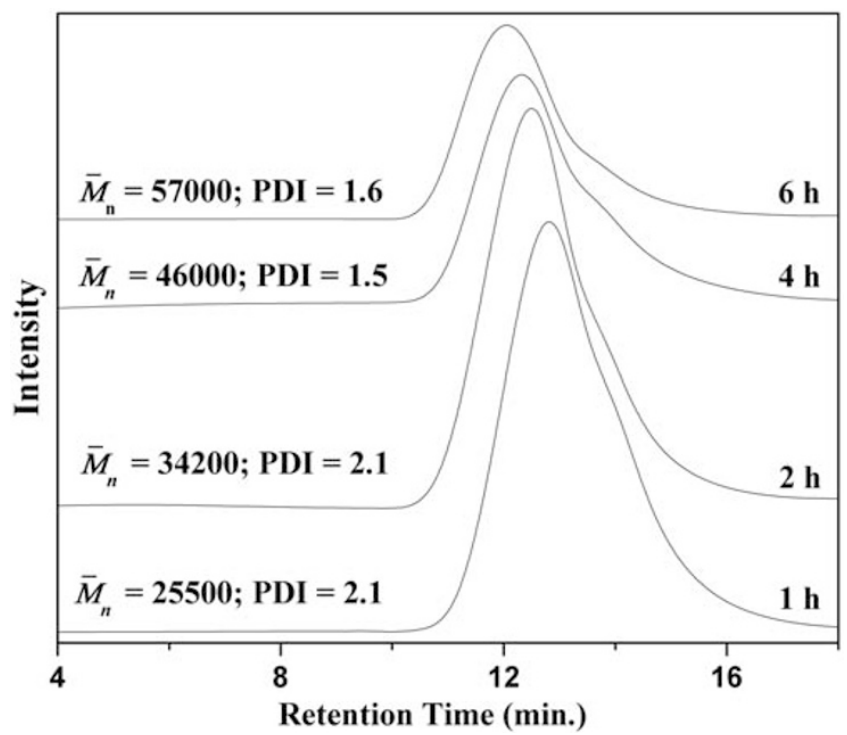

Figure 6 GPC curves for MMA polymerization using TPEBMP.

As the methyl protons and phenyl protons of iniferter fragments are merged with the repeating units of polystyrene, the molecular weight of polystyrene could not be determined by ${ }^{1} \mathrm{H}$ NMR spectroscopy. However, the polymerization of styrene through this iniferter is confirmed by the presence of $\mathrm{C}=\mathrm{O}$ stretching vibrations of terminal ester groups present in the FT-IR spectrum of polystyrene.

\section{Thermal studies of polymers}

Finally, polymers synthesized using TPEBMP were characterized by differential scanning calorimetric and thermogravimetric analysis. Figure 9 shows the differential scanning calorimetric curves of PMMA (SM6) and polystyrene (SS12), and the glass transition temperature $\left(T_{\mathrm{g}}\right)$ values were determined as the middle point between the onset and offset points. The $T_{\mathrm{g}}$ values of PMMA and polystyrene are $127^{\circ} \mathrm{C}$ and $102^{\circ} \mathrm{C}$, respectively, which are similar to the values reported in the literature. ${ }^{28,29}$ In general, the thermal degradation of 
PMMA that is prepared by conventional free radical polymerization under a nitrogen atmosphere proceeds in three steps corresponding to head-to-head linkage $\left(\sim 165^{\circ} \mathrm{C}\right)$, initiation of chain ends from the vinylidene ends $\left(\sim 270^{\circ} \mathrm{C}\right)$ and random scission within the PMMA chain $\left(\sim 360^{\circ} \mathrm{C}\right) .{ }^{30}$ In contrast, the PMMA synthesized here undergoes two stages of decomposition, initially at around $170{ }^{\circ} \mathrm{C}$ and later at $320^{\circ} \mathrm{C}$, corresponding to the cleavage of head-to-head linkages

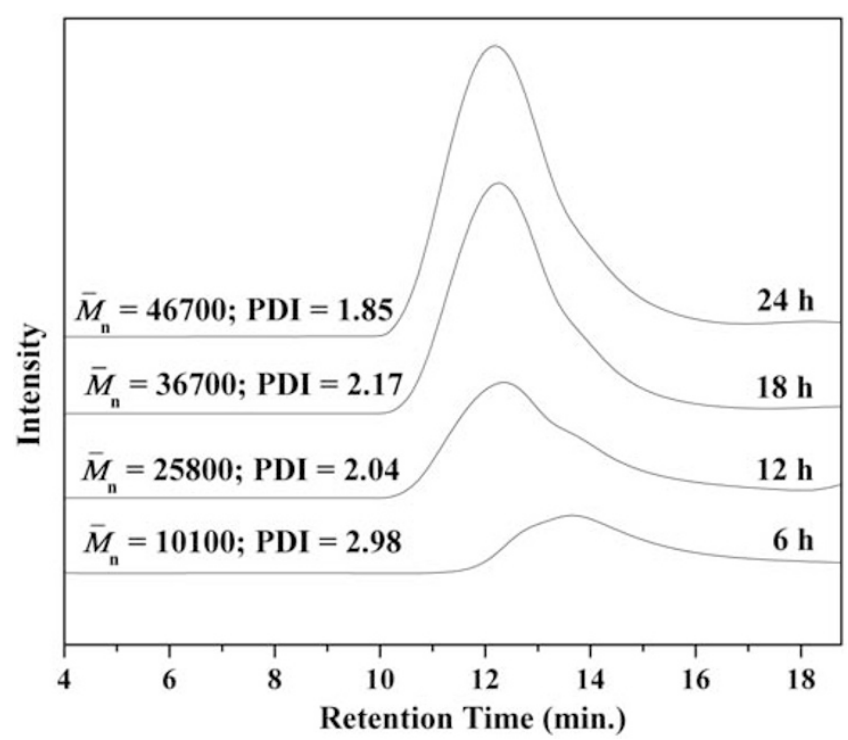

Figure 7 GPC curves for styrene polymerization using TPEBMP. followed by the random scission of PMMA chains. The absence of vinylidene end cleavage shows that MMA polymerization through the TPEBMP iniferter does not proceed through conventional radical polymerization, but rather through CRP. Similarly, single stage decomposition was observed at around $390^{\circ} \mathrm{C}$ for polystyrene, which is also evidence of the absence of vinylidene end groups and the presence of CRP.

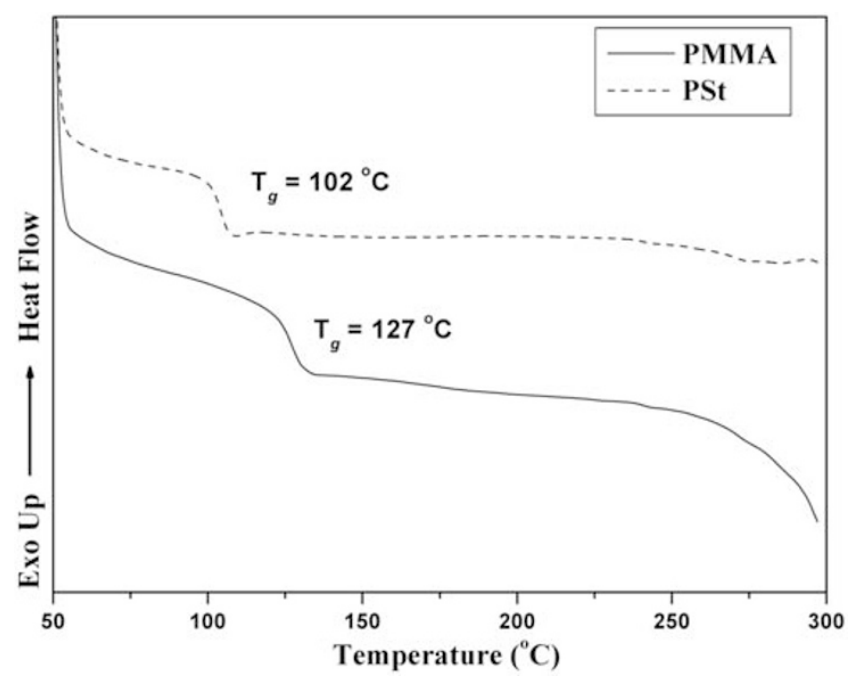

Figure 9 Differential scanning calorimetric curves of PMMA (SM6) and polystyrene (SS12) synthesized using TPEBMP.

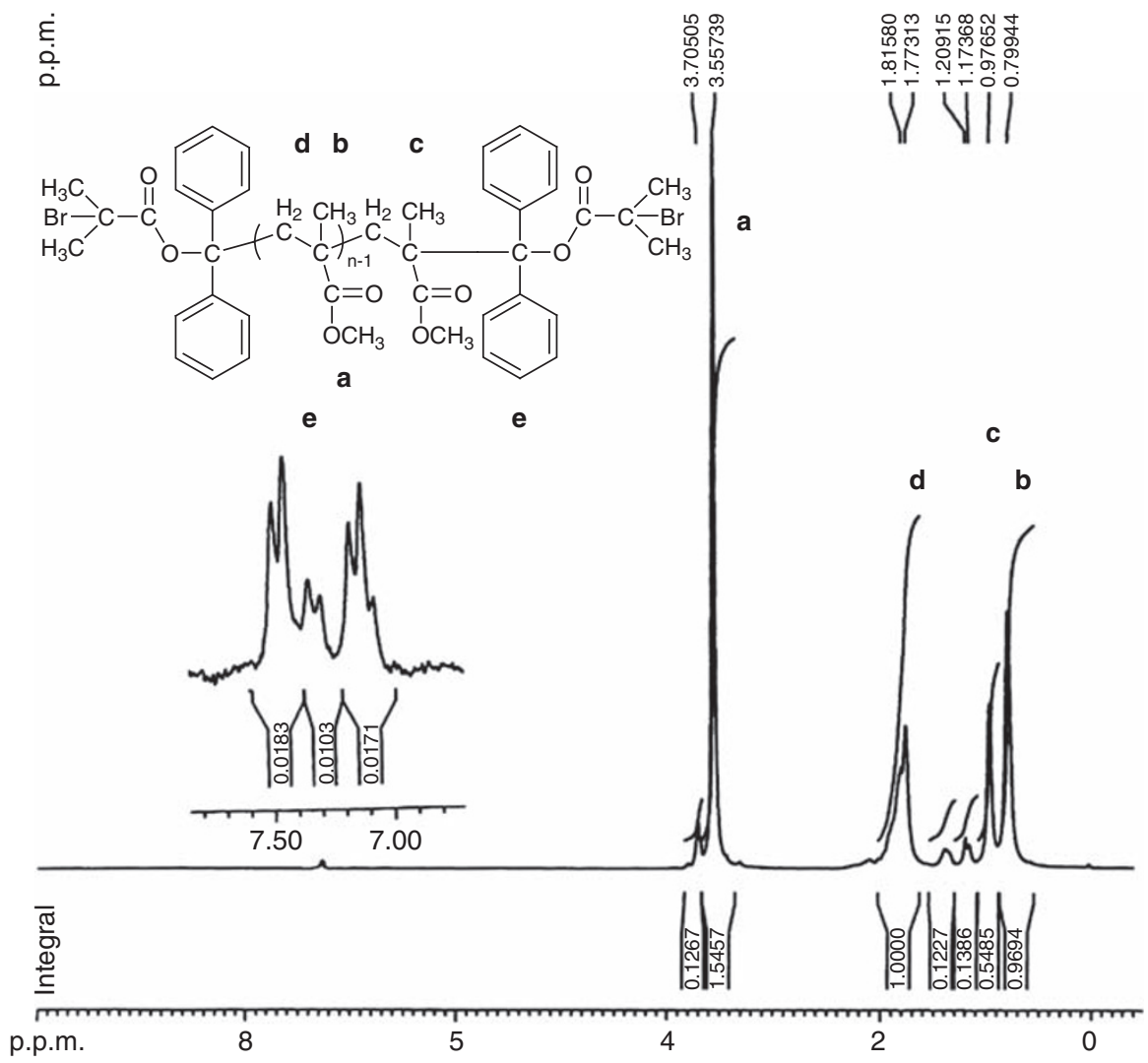

Figure $8{ }^{1} \mathrm{H}$ NMR spectrum of PMMA (SM6) synthesized using TPEBMP. 


\section{CONCLUSIONS}

A novel bromine-containing thermal iniferter was successfully prepared and used to polymerize MMA and styrene. A linear increase in the number average molecular weight was observed with increasing monomer conversion. Similarly, linear increases were observed in time vs conversion and time vs $\ln \left([M]_{0} /[M]\right)$ plots. These results indicate that the novel iniferter polymerizes MMA and styrene via a CRP mechanism. Because the novel functional thermal iniferter polymerizes styrene and MMA through CRP, this iniferter can be incorporated into nano-clay, and the resulting nano-clay can be used to polymerize vinyl and acrylate type monomers to prepare polymer-clay nanocomposites.

Thermogravimetric analysis curves of PMMA and polystyrene prepared using TPEBMP and ${ }^{1} \mathrm{H}$ NMR spectrum of polystyrene prepared using TPEBMP are available as Supplementary Information.

\section{ACKNOWLEDGEMENTS}

We thank the Department of Science and Technology, New Delhi, India for financial support of this research (SR/NM/NS-45/2007, dated 26.02.2009). MK would like to thank The Ministry of Social Justice and Empowerment and The Ministry of Tribal Affairs, Government of India, for providing financial support for this work through a Rajiv Gandhi National Fellowship.

1 Szwarc, M., Levy, M. \& Milkovich, R. Polymerization initiated by electron transfer to monomer. A new method of formation of block polymers. J. Am. Chem. Soc. 78, 2656-2657 (1956).

2 Quirk, R. P., Mathers, R. T., Cregger, T. \& Foster, M. D. Anionic synthesis of block copolymer brushes grafted from a 1,1-diphenylethylene monolayer. Macromolecules 35, 9964-9974 (2002).

3 Yagci, Y. \& Tasdelen, M. A. Mechanistic transformations involving living and controlled/ living polymerization methods. Prog. Polym. Sci. 31, 1133-1170 (2006).

4 Braunecker, W. A. \& Matyjaszewski, K. Controlled/living radical polymerization: features, developments, and perspectives. Prog. Polym. Sci.32, 93-146 (2007).

5 Wang, J. S. \& Matyjaszewski, K. Controlled/'Living' radical polymerization. Halogen atom transfer radical polymerization promoted by a $\mathrm{Cu}(\mathrm{I}) / \mathrm{Cu}(\mathrm{II})$ redox process. Macromolecules 28, 7901-7910 (1995).

6 Goto, A. \& Fukuda, T. Kinetic study on nitroxide-mediated free radical polymerization of tert-butyl acrylate. Macromolecules 32, 618-623 (1999).

7 Barre, G., Taton, D., Lastecoueres, D. \& Vincent, J. M. Closer to the 'Ideal recoverable catalyst' for atom transfer radical polymerization using a molecular non-fluorous thermomorphic system.. J. Am. Chem. Soc. 126, 7764-7765 (2004).

8 Otsu, T. \& Yoshida, M. Role of initiator-transfer agent-terminator (iniferter) in radical polymerizations: polymer design by organic disulfides as iniferters. Makromol. Chem. Rapid Commun. 3, 127-132 (1982).

9 Otsu, T., Yoshida, M. \& Tazaki, T. A model for living radical polymerization. Makromol. Chem. Rapid Commun. 3, 133-140 (1982).
10 Nakayama, Y., Sudo, M., Uchida, K. \& Matsuda, T. Spatio-resolved hyperbranched graft polymerized surfaces by iniferter-based photograft copolymerization. Langmuir 18, 2601-2606 (2002).

11 Takayuki, O., Yamashita, K. \& Tsuda, K. Synthesis, reactivity, and role of 4-vinylbenzyl $\mathrm{N}, \mathrm{N}$-diethyldithiocarbamate as a monomer-iniferter in radical polymerization. Macromolecules 19, 287-290 (1986).

12 Qin, S. H. \& Qiu, K. Y. Polymerization of vinyl monomers using a novel trifunctional iniferter. J. Polym. Sci.: Part A: Polym. Chem. 38, 2115-2120 (2000).

13 Otsu, T. \& Tazaki, T. Living radical polymerization in homogeneous system with phenylazotriphenylmethane as a thermal iniferter. Polymer Bulletin 16, 277-284 (1986).

14 Suwier, D. R., Teerenstra, M. N., Vanhaecht, B. \& Koning, C. E. Flexibilized styrene- $\mathrm{N}$-substituted maleimide copolymers. II. Multiblock copolymers prepared from PTHF-based iniferters. J. Polym. Sci., Polym. Chem. Edn. 38, 3558-3568 (2000).

15 Bledzki, A., Braun, D. \& Titlschkau, K. Polymerisation von methylmethacrylat mit verschiedenen tetraphenylethanen. Makromol. Chem. 184, 745-754 (1983).

16 Chen, X. P., Quu, K. Y., Swift, G., Westmoreland, D. G. \& Wu, S. A novel thermal iniferter for radical polymerization. Eur. Polym. J. 36, 1547-1554 (2000).

17 Otsu, T., Matsumoto, A. \& Tazaki, T. Radical polymerization of methyl methacrylate with some 1,2-disubstituted tetraphenylethanes as thermal iniferter. J. Polym. Bull. 17, 323-330 (1987).

18 Guo, Z., Yang, G., Wan, D. \& Huang, J. Controllable radical copolymerization of styrene and methyl methacrylate using 1,1,2,2-tetraphenyl-1,2-bis(trimethylsilyloxy) ethane as initiator. J. App. Polym. Sci. 82, 1474-1482 (2001).

19 Bledzki, A. \& Braun, D. Polymerisation von methylmethacrylat mit 1,1,2,2tetrapheny1-1,2-diphenoxyethan. Makromol. Chem. 182, 1047-1056 (1982).

20 Braun, D. \& Becker, K. H. Aromatic pinacols as polymerization initiators. Ind. Eng. Chem. Prod. Res. Develp. 10, 386-388 (1971).

21 Braun, D. \& Becker, K. Aromatische pinakole als polymerisations initiatoren. Angew. Makromol. Chem. 6, 186-189 (1969).

22 Tharanikkarasu, K. \& Radhakrishnan, G. A novel polyurethane macroinitiator for free radical polymerization. Eur. Polym. J. 30, 1351-1355 (1994).

23 Tharanikkarasu, K. \& Radhakrishnan, G. Tetraphenylethane iniferters. II. Toluene diisocyanate-based polyurethane iniferter for 'Living' radical polymerization of acrylonitrile. J. Polym. Sci.: Part A: Polym. Chem. 34, 1723-1731 (1996).

24 Furniss, B. S., Hannaford, A. J., Smith, P. W. G. \& Tatchell, A. R. Vogel's Textbook of Practical Organic Chemistry 528 (Pearson Education Ltd./Longman, Delhi/London, 2004).

25 Lu, G., Li, Y.- M., Lu, C.-h., Xu, Z.- Z. \& Zhang, H. N-[2-(8-heptadecenyl)-4,5-dihydro$1 \mathrm{H}$-imidazole-1-ethyl]-2-bromoisbutyramide as iniutiator for atom transfer radical polymerization (ATPR) and surface-initiated ATRP of methacrylate on iron. Polym. Bull. 65, 227-244 (2010).

26 Qin, S.- H., Quu, K.- Y., Westmoreland, D. G., Lau, W., Wu, S. \& Swift, G. Polymerization of methyl methacrylate with a thermal iniferter: diethyl 2,3-dicyano-2,3-di(p-tolyl)succinate. J. App. Polym. Sci. 80, 2566-2572 (2001).

27 Xiao, G., Hong, X., Zhang, H. \& Zhou, X. A novel ligand for atom transfer radical polymerization. Polym. Bull. 62, 777-789 (2009).

28 Wunderlich, W. in Physical Constants of poly(methyl methacrylate) (eds. Brandrup J. \& Immergut E. H.), Polymer Handbook, V/78 (John Wiley \& Sons, Toronto, 1989).

29 Rudd, J. F. in Physical Constants of poly(styrene) (eds. Brandrup J. \& Immergut E. H.), Polymer Handbook, V/81 (John Wiley \& Sons, Toronto, 1989).

30 Kashiwagi, T., Inaba, A., Brown, J. E., Hatada, K., Kitayama, T. \& Masuda, E. Effects of weak linkages on the thermal and oxidative degradation of poly(methyl methacrylates). Macromolecules 19, 2160-2168 (1986).

Supplementary Information accompanies the paper on Polymer Journal website (http://www.nature.com/pj) 